\title{
Water exchange rates of water-soluble manganese(III) porphyrins of therapeutical potential $\uparrow$
}

\author{
Ana Budimir, ${ }^{a}$ József Kalmár, ${ }^{* b}$ István Fábián, ${ }^{b}$ Gábor Lente,,${ }^{b}$ István Bányai, ${ }^{c}$ Ines Batinić-Haberle ${ }^{d}$ and \\ Mladen Biruš $* a$
}

\author{
Received 16th December 2009, Accepted 19th February 2010 \\ First published as an Advance Article on the web 26th March 2010 \\ DOI: $10.1039 / \mathrm{b} 926522 \mathrm{~h}$
}

\begin{abstract}
The activation parameters and the rate constants of the water-exchange reactions of $\mathrm{Mn}^{\mathrm{III}} \mathrm{TE}-2-\mathrm{PyP}^{5+}$ (meso-tetrakis( $N$-ethylpyridinium-2-yl)porphyrin) as cationic, $\mathrm{Mn}^{\mathrm{III}} \mathrm{TnHex}-2-\mathrm{PyP}^{5+}$ (meso-tetrakis( $N$-n-hexylpyridinium-2-yl)porphyrin) as sterically shielded cationic, and $\mathrm{Mn}^{\mathrm{III}} \mathrm{TSPP}^{3-}$ (meso-tetrakis(4-sulfonatophenyl)porphyrin) as anionic manganese(III) porphyrins were determined from the temperature dependence of ${ }^{17} \mathrm{O}$ NMR relaxation rates. The rate constants at $298 \mathrm{~K}$ were obtained as $4.12 \times 10^{6} \mathrm{~s}^{-1}, 5.73 \times 10^{6} \mathrm{~s}^{-1}$, and $2.74 \times 10^{7} \mathrm{~s}^{-1}$, respectively. On the basis of the determined entropies of activation, an interchange-dissociative mechanism $\left(I_{\mathrm{d}}\right)$ was proposed for the cationic complexes $\left(\Delta S^{\ddagger}=\sim 0 \mathrm{~J} \mathrm{~mol}^{-1} \mathrm{~K}^{-1}\right)$ whereas a limiting dissociative mechanism (D) was proposed for $\mathrm{Mn}^{\text {III TSPP }}{ }^{3-}$ complex $\left(\Delta S^{\ddagger}=+79 \mathrm{~J} \mathrm{~mol}^{-1} \mathrm{~K}^{-1}\right)$. The obtained water exchange rate of $\mathrm{Mn}^{\mathrm{III}} \mathrm{TSPP}^{3-}$ corresponded well to the previously assumed value used by Koenig et al. (S. H. Koenig, R. D. Brown and M. Spiller, Magn. Reson. Med., 1987, 4, 52-260) to simulate the ${ }^{1} \mathrm{H}$ NMRD curves, therefore the measured value supports the theory developed for explaining the anomalous relaxivity of $\mathrm{Mn}^{\mathrm{III}} \mathrm{TSPP}^{3-}$ complex. A magnitude of the obtained water-exchange rate constants further confirms the suggested inner sphere electron transfer mechanism for the reactions of the two positively charged Mn(III) porphyrins with the various biologically important oxygen and nitrogen reactive species. Due to the high biological and clinical relevance of the reactions that occur at the metal site of the studied Mn(III) porphyrins, the determination of water exchange rates advanced our insight into their efficacy and mechanism of action, and in turn should impact their further development for both diagnostic (imaging) and therapeutic purposes.
\end{abstract}

\section{Introduction}

Reactive oxygen and nitrogen species have been implicated in numerous pathological conditions including inflammation, ischemia/reperfusion, hemorrhagic shock, autoimmune diseases, neurological disorders, radiation injuries, carcinogenesis and senescence. $^{1-4}$ With $\mathrm{Mn}$ as an innocent metal center (lacking Fenton chemistry-related toxicity), and the porphyrin cyclic structure that provides both a high metal/ligand complex stability and the rich biologically relevant redox chemistry at the Mn site, Mn(III) porphyrins and their derivatives have been successfully developed as SOD mimics. ${ }^{2-11}$ The most efficacious orthoMn(III) $N$-alkylpyridylporphyrins possess electron-withdrawing positively charged quaternized pyridyl substituents close to the metal site which, alike SOD enzymes themselves, allows: (1) the $\mathrm{Mn}^{\mathrm{III}} / \mathrm{Mn}^{\mathrm{II}}$ reduction potential to be in the desirable range,

${ }^{a}$ Faculty of Pharmacy and Biochemistry, University of Zagreb, Ante Kovačića 1,10000,Zagreb,Croatia.E-mail: birus@pharma.hr

${ }^{b}$ Department of Inorganic and Analytical Chemistry, University of Debrecen, Debrecen 10, POB 21, Hungary H-4010.E-mail: jkalmar@, dragon.unideb.hu

'Department of Colloid and Environmental Chemistry, University of Debrecen, Hungary

${ }^{d}$ Duke University Medical School, Department of Radiation Oncology, Durham, NC, 27710, USA

$\dagger$ Electronic supplementary information (ESI) available: Computational details. See DOI: 10.1039/b926522h (around $+300 \mathrm{mV} v s$. NHE), and (2) electrostatic facilitation for the approach of negatively charged superoxide, $\mathrm{O}_{2}{ }^{--}$. In addition to the antioxidant capacity, bioavailability of the Mn porphyrins is essential for their high in vivo ability to reduce oxidative stress injuries. Thus lipophilic analogues were later synthesized that more readily cross the lipid membranes and/or the bloodbrain barrier. ${ }^{4}$ The most potent antioxidants in vitro, ${ }^{4,6}$ and in vivo, ${ }^{11-15}$ the ortho isomers of $\mathrm{Mn}$ (III) $N$-alkyl-, $N$-methoxyalkyland $N$-tri(ethyleneglycol)porphyrins, are also reactive towards biologically reactive oxygen or nitrogen species other than the superoxide anion, in particular towards peroxynitrite. ${ }^{16,17}$ The high reactivity of $\mathrm{Mn}$ (III) porphyrins towards small molecules, coupled with their ability to undergo fast axial-ligand substitution reactions while redox cycling, presents an essential aspect of both their in vivo and in vitro solution-phase chemistry. Though of insignificant SOD-like activity, ${ }^{8,17}$ the anionic $\mathrm{MnTSPP}^{3-}$ possesses considerable ability to reduce peroxynitrite $\left(\log k_{\text {red }}\left(\mathrm{ONOO}^{-}\right)=\right.$ $5.53),{ }^{18}$ which justifies its use in studying oxidative stress injuries, particularly from mechanistic point of view (electrostatics, anion effect with respect to its level and site of accumulation and effects observed).

The axial interaction of water with the central metal ion is of fundamental importance in both the ligand-substitution and redox processes of metalloporphyrins in aqueous solution. In the case of iron-porphyrin complexes, the rates and the mechanism of water exchange were satisfactorily elucidated. ${ }^{19}$ 
$\mathrm{Fe}^{\mathrm{III}} \mathrm{TSPP}^{3-}$ as anionic, Fe ${ }^{\mathrm{III}} \mathrm{TM}-4-\mathrm{PyP}^{5+}$ (Fe(III) meso-tetrakis( $N$ methylpyridinium-4-yl)porphyrin) as cationic and $\mathrm{Fe}^{\mathrm{III}} \mathrm{TMPS}^{\mathrm{n}-}$ (Fe(III) meso-tetrakis(sulfonatomesithyl)porphyrin) as sterically shielded anionic complexes were studied. For all three complexes a dissociative mode of activation was suggested on the basis of positive activation entropy and activation volume. For the third complex the limiting dissociative (D) mechanism was proposed because of the presence of bulky mesityl groups, while for the first two complexes a dissociative interchange mechanism, $I_{\mathrm{D}}$, was proposed. The water exchange of negatively charged $\mathrm{Fe}^{\mathrm{III}} \mathrm{TSPP}^{3-}$ is five times faster than that of $\mathrm{Fe}^{\mathrm{III}} \mathrm{TM}-4-\mathrm{PyP}^{5+}$ indicating a labilizing effect of the increased electron density on the metal ion center.

Due to high biological and clinical relevance of the reactions of $\mathrm{Mn}$ (III) porphyrins with reactive species that occur at the metal site, we found it important to determine the water exchange rates for $\mathrm{Mn}$ (III) porphyrins that would further increase our insight into their efficacy and mechanism of action, and in turn impact their further development for both diagnostic (imaging, vide infra) and therapeutic purposes. Three complexes shown in the drawing (Fig. 1) are chosen in this study. Among them $\mathrm{Mn}^{\mathrm{III}} \mathrm{TE}-2-\mathrm{PyP}^{5+}$ and $\mathrm{Mn}^{\text {III }}$ TnHex-2-PyP ${ }^{5+}$ have been the most widely studied and remarkably effective in decreasing oxidative stress injuries. ${ }^{11-15,17}$
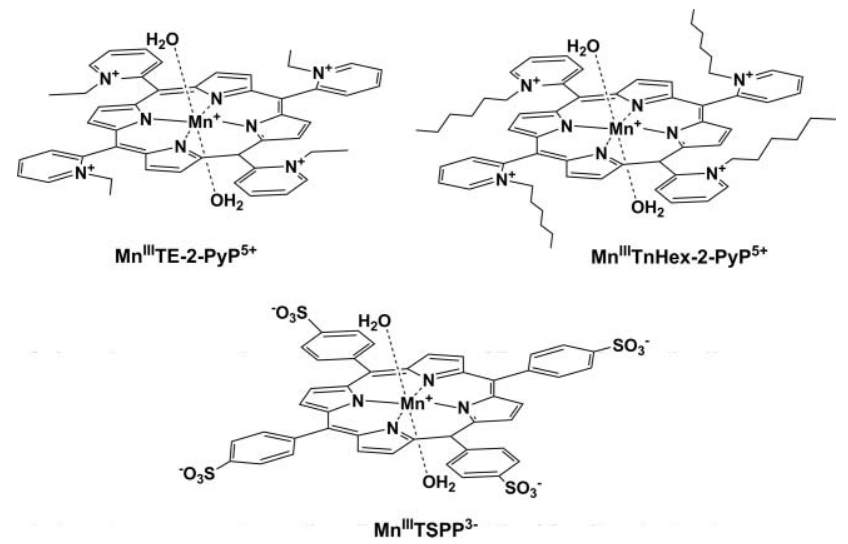

Fig. 1 The structure of the Mn(III) porphyrins studied with axially coordinated water molecules indicated.

Since as early as 1924 it has been well accepted that both porphyrins and their metal complexes have affinity for malignant tissues. ${ }^{20}$ This feature has led to their extensive application in nuclear medicine, X-ray and MRI. With many papers describing the possible application of $\mathrm{Mn}$ (III) porphyrins as tumor imaging agent, ${ }^{21,22}$ A. G. Schering was awarded a patent for the use of Mn(III) porphyrins as tumor enhancing MRI contrast agents. The majority of the published papers dealt with $\mathrm{Mn}^{\mathrm{III}} \mathrm{TSPP}^{3-}$. In 1990 Nelson and his co-workers ${ }^{23}$ proposed the safe use of this porphyrin as an effective liver specific MRI contrast agent. Although other manganese metalloporphyrins were also studied and tested, to date only a non-porphyrin MnDPDP, manganese(II) dipyridoxyldiphosphate, (Mangafodipir Trisodium ${ }^{\mathrm{TM}}$, initially synthesized by Rocklage et al. in 1989) reached phase III clinical trials for the detection of liver tumors. The $\mathrm{Mn}^{\mathrm{III}} \mathrm{TSPP}^{3-}$ has a high relaxivity, which was found to be even higher when bound to a bovine serum albumin due to a preference of $\mathrm{Mn}$ monomeric high spin state. ${ }^{24}$ The application of $\mathrm{Mn}^{\mathrm{III}} \mathrm{TSPP}^{3-}$ in human medicine is precluded by its relatively high toxicity. The effective dose for sufficient contrast (at 2 Tesla) is reported to be only five times lower than $L D_{50}{ }^{25}$ Therefore, $\mathrm{Mn}^{\mathrm{III}} \mathrm{TSPP}^{3-}$ is considered useful in radioactive $\left({ }^{51} \mathrm{Mn}\right)$ nuclear medicine rather than in MRI. ${ }^{26}$

It was also recently shown that $\mathrm{Mn}^{\mathrm{III}} \mathrm{TE}-2-\mathrm{PyP}^{5+}$ and $\mathrm{Mn}^{\text {III }} \mathrm{TnHex}-2-\mathrm{PyP}^{5+}$ exhibit powerful potentials as molecular MR imaging probes for the prostate cancer detection and may be particularly effective at selectively detecting multifocal disease in situ ${ }^{27}$ Their unusually high $T_{1}$ relaxivities in comparison with commercially available gadolinium chelates lowers the detection limits within the micromolar range at 7 Tesla. In vivo, $\mathrm{Mn}^{\mathrm{III}} \mathrm{TE}-2-$ $\mathrm{PyP}^{5+}$ and $\mathrm{Mn}^{\mathrm{III}} \mathrm{TnHex}-2-\mathrm{PyP}^{5+}$ selectively accumulate in prostate tumors with 10-11-fold greater relaxation changes than in normal prostate gland. ${ }^{27}$

The relaxivity of $\mathrm{Mn}^{\mathrm{III}} \mathrm{TSPP}^{3-}$ for water protons is unexpectedly high, as reported in many papers and summarized by Schaefle and Sharp, ${ }^{28}$ mainly because of the high inner sphere relaxation term. The NMR dispersion curves of $T_{1}$ were described as unique for both shape and values. ${ }^{29}$ The results could not be interpreted by Solomon-Blombergen-Morgan theory. ${ }^{30,31}$ The relaxation behavior of $\mathrm{Mn}^{\mathrm{III}} \mathrm{TSPP}^{3-}$ of $S=2$ spin state is particularly interesting from the relaxation theory point of view. Schaefle and Sharp ${ }^{28}$ showed in their study of NMRD profile in liquid and gel phases that the profiles could be satisfactorily described by accounting for the effects of Brownian motion on the splitting of the $m_{\mathrm{s}}= \pm 2$ and on the corresponding correlation time. The most extensive study of relaxivity of $\mathrm{Mn}^{\mathrm{III}} \mathrm{TSPP}^{3-}$ in comparison to $\mathrm{Fe}^{\mathrm{III}} \mathrm{TSPP}^{3-}$ was published by Koenig et al. ${ }^{29}$ In calculations $10 \mathrm{~ns}$, as the average residence time of the water in the coordination sphere for both iron and manganese porphyrin complexes, was applied. Since 1980 a value of $1.4 \times 10^{7} \mathrm{~s}^{-1}$ was cited for the water exchange rate constants of $\mathrm{Fe}^{\mathrm{III}} \mathrm{TSPP}^{3-}{ }^{32}$ but it was later redetermined as $2 \times 10^{6} \mathrm{~s}^{-1} \cdot{ }^{19}$ From these values the average residence time is calculated as $100-500 \mathrm{~ns}$ for the iron complex; the higher limit seems to be more reliable. In spite of this remarkable progress in describing magnetic aspects of anomalous relaxivity of $\mathrm{Mn}^{\mathrm{III}} \mathrm{TSPP}^{3-}$ another important factor, i.e. its water exchange rate constant thus far has not been reported.

Herein, we describe the temperature dependent ${ }^{17} \mathrm{O}$ NMR measurements performed in order to determine the residence time of axially coordinated water molecules in Mn(III) porphyrins and the values of the water-exchange activation parameters. Mechanistic conclusions regarding the water exchange of the studied Mn(III) porphyrins could be drawn from the experimental results. We also evaluated the reflections of the water-exchange kinetic results on the intimate mechanisms of the disproportionation/dismutation of superoxide and on the reduction of some other reactive oxygen and nitrogen reactive species.

\section{Experimental}

\section{Sample preparation}

All solutions were prepared by weight. The three investigated Mn(III) porphyrin complexes were synthesized according to reported procedures. ${ }^{3,47}$ They were dissolved in double ionexchanged and ultrafiltered water (MILLIPORE from MilliQ) and the $\mathrm{pH}$, measured with a combined glass electrode calibrated with buffers (Metrohm), was adjusted by adding 
measured volumes of aqueous solutions of hydrochloric acid or sodium hydroxide of known concentrations. ${ }^{17} \mathrm{O}$-enriched water (10 at $\%$, Amersham, UK) was added to the solutions for the ${ }^{17} \mathrm{O}$ NMR measurements in order to improve sensitivity. The final concentrations of the solutions of $\mathrm{Mn}$ (III) porphyrins were $10.0 \pm 0.5 \mathrm{mmol}$ per $\mathrm{dm}^{3}$. Reference solutions were prepared from tetraethylammonium chloride (TEA) (Sigma-Aldrich). The concentration and the $\mathrm{pH}$ of the references were the same as of the porphyrin solutions.

\section{${ }^{17} \mathrm{O}$ NMR}

Variable-temperature ${ }^{17} \mathrm{O}$ NMR measurements were performed using Bruker DRX-400 (9.4 T, 54.2 MHz) or DRX-360 (8.5 T, 48.8 $\mathrm{MHz}$ ) spectrometers. Homemade air-circulating and Eurotherm temperature control units were used to stabilize the temperature. The sample temperatures were corrected using the "methanol thermometer" method. ${ }^{33}$ The samples were left for $15 \mathrm{~min}$ before each measurement to adjust to the given temperature. The change in temperature was always less or equal to $5 \mathrm{~K}$. The samples were sealed in $5 \mathrm{~mm}$ NMR tubes. Longitudinal relaxation rates, $1 / T_{1}$, were obtained by the inversion recovery method ${ }^{34}$ and transverse relaxation rates, $1 / T_{2}$, directly from the line widths.

\section{Results and discussion}

The data were analysed according to Powel and Merbach's previously published procedure. ${ }^{35}$ From the measured ${ }^{17} \mathrm{O}$ NMR relaxation rates and angular frequencies of the $\mathrm{Mn}$ (III) porphyrin solutions, $1 / T_{1}, 1 / T_{2}$, and $\omega$, and of the TEA reference solutions, $1 / T_{1 A}, 1 / T_{2 A}$, and $\omega_{\mathrm{A}}$, one can calculate the reduced relaxation rates and the chemical shift, $1 / T_{1 r}, 1 / T_{2 r}$, and $\Delta \omega_{\mathrm{r}}$, which may be written as in eqn (1)-(3) where $1 / T_{1 m}$ and $1 / T_{2 m}$ are the relaxation rates in the bound water, $\Delta \omega_{\mathrm{m}}$ is the chemical shift difference between the bound water and bulk water (in the absence of a paramagnetic interaction with the bulk water), $P_{\mathrm{m}}$ is the mole fraction of bound water, and $\tau_{\mathrm{m}}$ is the mean residence time (or inverse exchange rate, $1 / \tau_{\mathrm{m}}=k_{\mathrm{ex}}$ ) of water molecules in the innercoordination sphere. The total outer-sphere contributions to the reduced relaxation rates and chemical shift are represented by $1 / T_{1 \mathrm{os}}, 1 / T_{2 \mathrm{os}}$, and $\Delta \omega_{\mathrm{os}}$.

$$
\begin{gathered}
\frac{1}{T_{1 \mathrm{r}}}=\frac{1}{P_{\mathrm{m}}}\left[\frac{1}{T_{1}}-\frac{1}{T_{1 \mathrm{~A}}}\right]=\frac{1}{T_{1 \mathrm{~m}}+\tau_{\mathrm{m}}}+\frac{1}{T_{1 \mathrm{os}}} \\
\frac{1}{T_{2 \mathrm{r}}}=\frac{1}{P_{\mathrm{m}}}\left[\frac{1}{T_{2}}-\frac{1}{T_{2 \mathrm{~A}}}\right]=\frac{1}{\tau_{\mathrm{m}}} \frac{T_{2 \mathrm{~m}}^{-2}+\tau_{\mathrm{m}}^{-1} T_{2 \mathrm{~m}}^{-1}+\Delta \omega_{\mathrm{m}}^{2}}{\left(\tau_{\mathrm{m}}^{-1}+T_{2 \mathrm{~m}}^{-1}\right)^{2}+\Delta \omega_{\mathrm{m}}^{2}}+\frac{1}{T_{2 \mathrm{os}}} \\
\Delta \omega_{\mathrm{r}}=\frac{1}{P_{\mathrm{m}}}\left(\omega-\omega_{\mathrm{A}}\right)=\frac{\Delta \omega_{\mathrm{m}}}{\left(1+\tau_{\mathrm{m}} T_{2 \mathrm{~m}}^{-1}\right)^{2}+\tau_{\mathrm{m}}^{2} \Delta \omega_{\mathrm{m}}^{2}}+\Delta \omega_{\mathrm{os}}
\end{gathered}
$$

The relaxation rates of the bound water $\left(1 / T_{1 m}, 1 / T_{2 m}\right)$ display an Arrhenius-like temperature dependence (eqn (4) with $i=1$, 2) where $A_{\text {im }}$ is a pre-exponential parameter (in $\mathrm{s}^{-1}$ ) and the dimensions of $E_{\text {im }}$ are the energies. The temperature dependence of the difference in chemical shift between the bound water and bulk water $\left(\Delta \omega_{\mathrm{m}}\right)$ is given by eqn (5) where $g_{\mathrm{L}}$ is the isotropic Landé $g$ factor $\left(g_{\mathrm{L}}=2.0\right.$ for $\left.\mathrm{Mn}^{3+}\right), S$ is the electron spin $(S=$ $4 / 2$ for $\left.\mathrm{Mn}^{3+}\right), A / \mathrm{h}$ is the hyperfine or scalar coupling constant
Table 1 The activation parameters and the rate constants at $298.15 \mathrm{~K}$ for the water exchange reactions of $\mathrm{Mn}$ (II) $)_{\mathrm{aq}}$ and three different $\mathrm{Mn}$ (III) porphyrin complexes

\begin{tabular}{lllll}
\hline & $k_{\text {ex }}{ }^{298} / \mathrm{s}^{-1}$ & $\begin{array}{l}\Delta H^{\ddagger} / \\
\mathrm{kJ} \mathrm{mol}^{-1}\end{array}$ & $\begin{array}{l}\Delta S^{\ddagger} / \mathrm{J} \\
\mathrm{mol}^{-1} \mathrm{~K}^{-1}\end{array}$ & Ref. \\
\hline MnTE-2-PyP $^{5+}$ & $4.12 \times 10^{6}$ & $36 \pm 3$ & $4 \pm 10$ & this work \\
MnTnHex-2-PyP $^{5+}$ & $5.73 \times 10^{6}$ & $34 \pm 7$ & $-2 \pm 23$ & $\begin{array}{l}\text { this work } \\
\text { MnTSPP }\end{array}$ \\
& $2.74 \times 10^{7-}$ & $54 \pm 5$ & $79 \pm 19$ & this work \\
Mn(II) $)_{\text {aq. }}$ & $2.0 \times 10^{8}$ & & & 29 \\
& $2.89 \times 10^{7}$ & $33.1 \pm 0.6$ & $9 \pm 2$ & this work \\
& $2.1 \times 10^{7}$ & 33.9 & 12.2 & 37 \\
\hline
\end{tabular}

(in s $\mathrm{s}^{-1}$ ), and $B$ is the magnetic field (in T). The binding time $\tau_{\mathrm{m}}$ (or reciprocal exchange rate, $k_{\mathrm{ex}}$ ) of water molecules in the inner sphere is assumed to obey the Eyring equation (eqn (6)) where $\Delta S^{\ddagger}$ and $\Delta H^{\ddagger}$ are the entropy and enthalpy of activation for the exchange process. The exchange rate at $298.15 \mathrm{~K}\left(k_{\mathrm{ex}}{ }^{298}\right)$ can be calculated by substituting this temperature into the Eyring equation.

$$
\begin{gathered}
1 / T_{i m}=A_{i m} e^{-\Delta E_{i m}^{\neq} / R T} \\
\Delta \omega_{m}=\frac{g_{L} \mu_{B} S(S+1) B}{3 k_{B} T} \frac{A}{\hbar} \\
k_{e x}=\frac{k_{B} T}{h} e^{-\Delta H^{\neq} / R T} e^{\Delta S^{\neq} / R}
\end{gathered}
$$

In order to validate our methodological approach, the exchange rate at $298.15 \mathrm{~K}$ and the activation parameters of the waterexchange reaction of $\mathrm{Mn}(\mathrm{II})_{\mathrm{aq}}$ in a slightly acidic solution were determined ( $\mathrm{Zn}(\mathrm{II})_{\mathrm{aq}}$ was the reference) and were found to be in good agreement with previously reported data (see Table 1). ${ }^{36,37}$

In highly basic solutions of $\mathrm{Mn}(\mathrm{III})$ porphyrin $(\mathrm{pH}=12.0)$, the ${ }^{17} \mathrm{O}$ relaxation rates and angular frequencies of bulk water were found to be within the experimental error range of the measured values of the reference solutions, indicating that the Mn(III) porphyrin complexes show no measurable relaxivity enhancement. That could be the case if no water molecule is coordinated to the inner-sphere of manganese(III) ion. Therefore, the proposed dominant porphyrin species at this $\mathrm{pH}$ for all three porphyrins must be the one in which only an oxo ligand is axially coordinated to the central Mn(III).$^{38}$ Furthermore, the contributions of outersphere water molecules to the reduced relaxation rates and the chemical shift must be negligible as well.

In slightly acidic solutions $(\mathrm{pH}=6.0)$, the temperature dependence of the reduced relaxation rates and the chemical shifts for the three Mn(III) porphyrin complexes are shown in Fig. 2. The maxima observed in the temperature dependence of $1 / T_{2 r}$ are characteristic of the changeover from the "fast exchange" regime at high temperatures, where $T_{2 m}$ is the dominant term in eqn (2), to the "slow exchange" regime at low temperatures, where $\tau_{\mathrm{m}}$ is the dominant term. The changeover between the fast and the slow exchange limits is also manifested in $\Delta \omega_{\mathrm{r}}$, the maxima in $1 / T_{2 r}$ corresponding to the points of inflection in $\Delta \omega_{\mathrm{r}}$.

The exchange rates at $298.15 \mathrm{~K}$ and the activation parameters of the water-exchange reactions of three $\mathrm{Mn}$ (III) porphyrins were determined by nonlinear Levenberg-Marquard least-squares fit to the experimental curves and are given in Table 1. The temperature dependence of the reduced relaxation times and the chemical 

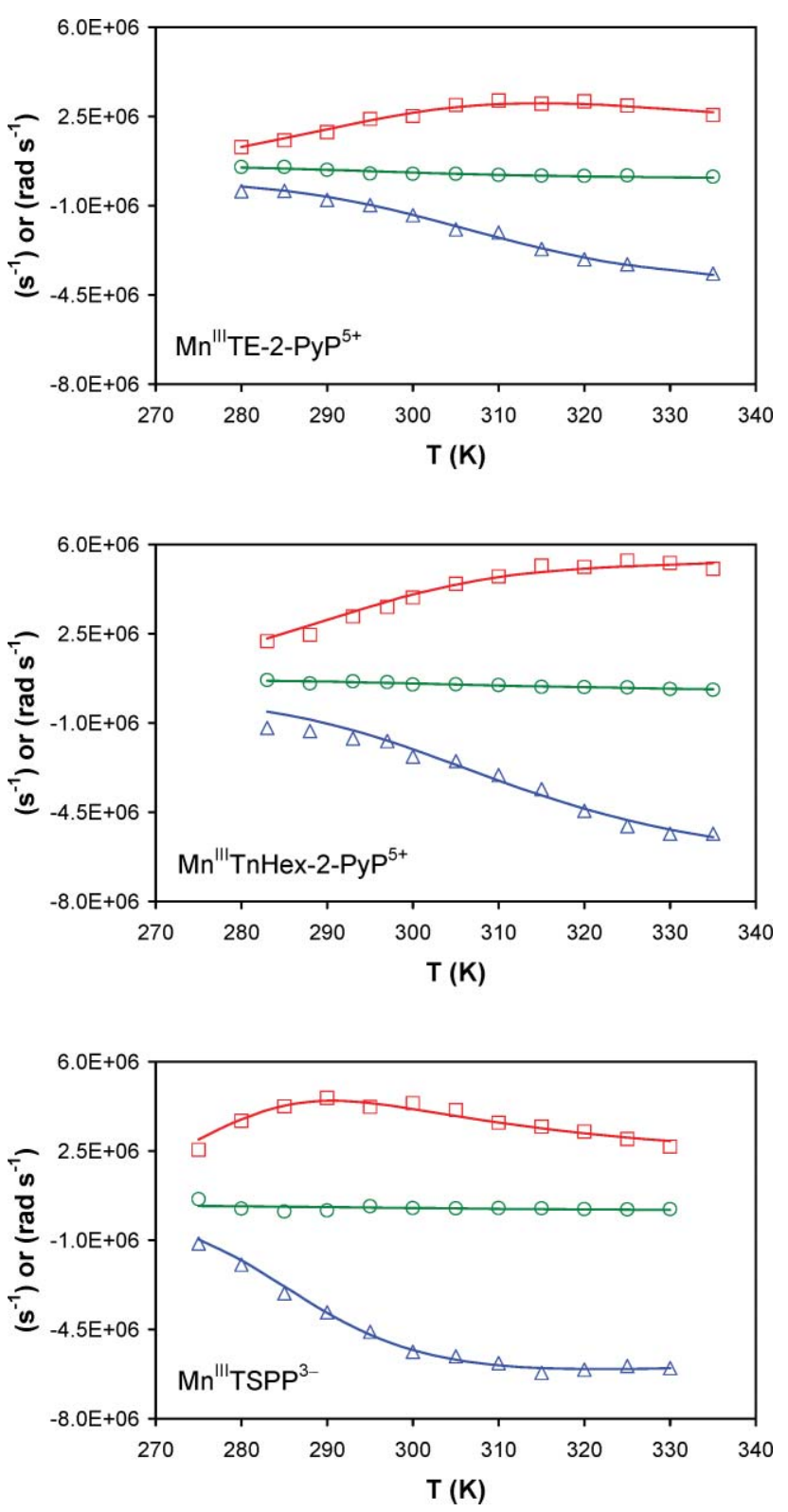

Fig. 2 The reduced relaxation rates (circles: $1 / T_{1 r}$ and squares: $1 / T_{2 r}$ in $\mathrm{s}^{-1}$ units) and the chemical shifts (triangles: $\Delta \omega_{\mathrm{r}}$ in $\mathrm{rad} \mathrm{s}^{-1}$ units) of the $\mathrm{Mn}$ (III) complexes studied as a function of temperature at $\mathrm{pH}$. The lines are the results of calculation by using eqn (1)-(3) and the appropriate parameters from Table 1.

shift of a given $\mathrm{Mn}(\mathrm{III})$ porphyrin were fitted simultaneously. As previously explained we used the full eqn (1)-(6), with setting of the outer-sphere terms to zero in the analysis, thus seven adjustable parameters were left in the least-squares fit: $A_{1 m}, E_{1 m}, A_{2 m}, E_{2 m}$, $A / \mathrm{h}, \Delta H^{\ddagger}$ and $\Delta S^{\ddagger}$.

The fastest exchange rate is observed for the negatively charged $\left[\left(\mathrm{H}_{2} \mathrm{O}\right)_{2} \mathrm{Mn}^{\mathrm{III}} \mathrm{TSPP}\right]^{3-}$ complex: $k_{\mathrm{ex}}{ }^{298}=2.74 \times 10^{7} \mathrm{~s}^{-1}$. The coordinated water molecules of the positively charged $\left[\left(\mathrm{H}_{2} \mathrm{O}\right)_{2} \mathrm{Mn}^{\mathrm{III}} \mathrm{TE}-2-\right.$ $\mathrm{PyP}]^{5+}$ and $\left[\left(\mathrm{H}_{2} \mathrm{O}\right)_{2} \mathrm{Mn}^{\mathrm{III}} \mathrm{TnHex}-2-\mathrm{PyP}\right]^{5+}$ complexes are definitely less labile with $k_{\mathrm{ex}}{ }^{298}=4.12 \times 10^{6} \mathrm{~s}^{-1}$ and $k_{\mathrm{ex}}{ }^{298}=5.73 \times$ $10^{6} \mathrm{~s}^{-1}$, respectively. Although the obtained first order rate constants for the water exchange on $\left[\left(\mathrm{H}_{2} \mathrm{O}\right)_{2} \mathrm{Mn}^{\mathrm{III}} \mathrm{TE}-2-\mathrm{PyP}\right]^{5+}$ and $\left[\left(\mathrm{H}_{2} \mathrm{O}\right)_{2} \mathrm{Mn}^{\mathrm{III}} \mathrm{TnHex}-2-\mathrm{PyP}\right]^{5+}$ complexes are an order of magnitude lower than the second order rate constants of both the one-electron oxidations of superoxide in neutral solution $\left(\log k=7.76\right.$ and 7.43 , respectively $\left.{ }^{4}\right)$ and the reductions of $\mathrm{ONOO}^{-}$and $\mathrm{CO}_{3}{ }^{--}$with $\left[\left(\mathrm{H}_{2} \mathrm{O}\right)_{2} \mathrm{Mn}^{\mathrm{III}} \mathrm{TE}-2-\mathrm{PyP}\right]^{5+},(\log k=7.53$ and 8.5 , respectively $\left.{ }^{16}\right)$, under in vivo and in vitro accessible concentrations the inner sphere electron transfer mechanisms are not precluded by the numerical values of the rates of waterexchange reactions. Indeed, our study on the dependence of the $k_{\text {cat }}\left(\mathrm{O}_{2}{ }^{-}\right)$of different isomers of $\mathrm{Mn}$ (III) $N$-alkylpyridylporphyrins upon the ionic strength indicates partial inner-sphere mechanism for $\mathrm{O}_{2}{ }^{--}$dismutation. ${ }^{6,39}$

An additional confirmation of this statement can be invoked by a detailed analysis of the reaction mechanism. The first step in the inner-sphere electron transfer mechanism is assumed to be a fast ion-pair formation equilibrium between the reactants, followed by the rate determining step of the aqua ligand substitution on the metal-ion center. According to the Fuoss equation, the ion-pair formation constant for the 5+ and 1- charged ionic reactants can be calculated as $K_{\mathrm{os}}=200-350 \mathrm{dm}^{3} \mathrm{~mol}^{-1}$ depending on the closest approach of the ions that is usually taken as 0.4 $0.5 \mathrm{~nm}$ when a water molecule separates them. ${ }^{40}$ Therefore the first order rate constants for the substitution of the water molecule by $\mathrm{O}_{2}{ }^{--}, \mathrm{ONOO}^{-}$and $\mathrm{CO}_{3}{ }^{--}(\log k \sim 5.2-6.2)$ are in a slightly better agreement with the water exchange rate constants obtained in the present study (log $k \sim 6.6-6.8)$ but the conformity can still be improved by considering various oversimplifications of the applied Fuoss equation. For instance, this way calculated rate constants of the water substitution and the obtained water exchange rate constants are not entirely comparable because of the solvation of the complex ions which statistically reduces the ligation rate constant for approximately an order of magnitude. That effect alone is sufficient for bringing the rate constants to the same order of magnitude. Furthermore, it was shown that the aromatic groups of the porphyrins provide a hydrophobic environment that may also change the accessibility of central metal ions to the negatively charged species involved in the above mentioned dismutation and reduction processes, ${ }^{41}$ as well that the charges of the complexes are either above or below the plane, which channels the negativelycharged reactants toward the axial positions of $\mathrm{Mn}$ porphyrin more efficiently. ${ }^{6}$ Both of the latter two effects are entirely ignored in the application of the Fuoss equation.

The activation enthalpy of the water-exchange reactions decreases from $54 \mathrm{~kJ} \mathrm{~mol}^{-1}\left(\left[\left(\mathrm{H}_{2} \mathrm{O}\right)_{2} \mathrm{Mn}^{\mathrm{III}} \mathrm{TSPP}\right]^{3-}\right)$ to $36 \mathrm{~kJ} \mathrm{~mol}^{-1}\left(\left[\left(\mathrm{H}_{2} \mathrm{O}\right)_{2} \mathrm{Mn}^{\text {III TE}} \mathrm{TE}-\mathrm{PyP}\right]^{5+}\right)$ and to $34 \mathrm{~kJ} \mathrm{~mol}^{-1}$ $\left(\left[\left(\mathrm{H}_{2} \mathrm{O}\right)_{2} \mathrm{Mn}^{\mathrm{III}} \mathrm{TnHex}-2-\mathrm{PyP}\right]^{5+}\right)$, but it is the effect of the activation entropy that causes the opposite tendency in the exchange rates. Namely, the smaller rate constants observed for the positively charged complexes are due to a significant decrease in $\Delta S^{\ddagger}$ from $+79 \mathrm{~J} \mathrm{~K}^{-1} \mathrm{~mol}^{-1}$ for $\left[\left(\mathrm{H}_{2} \mathrm{O}\right)_{2} \mathrm{Mn}^{\mathrm{III}} \mathrm{TSPP}\right]^{3-}$ to $\sim 0 \mathrm{~J} \mathrm{~K}^{-1} \mathrm{~mol}^{-1}$ for both $\left[\left(\mathrm{H}_{2} \mathrm{O}\right)_{2} \mathrm{Mn}^{\mathrm{III}} \mathrm{TE}-2-\mathrm{PyP}\right]^{5+}$ and $\left[\left(\mathrm{H}_{2} \mathrm{O}\right)_{2} \mathrm{Mn}^{\mathrm{III}} \mathrm{TnHex}-2-\right.$ $\mathrm{PyP}]^{5+}$. The large positive value of the activation entropy suggests a limiting dissociative water-exchange mechanism for the $\left[\left(\mathrm{H}_{2} \mathrm{O}\right)_{2} \mathrm{Mn}^{\mathrm{III}} \mathrm{TSPP}\right]^{3-}$, whereas the close to zero obtained entropy values are indicative of the interchange mechanism for the other two complexes.

According to van Eldik and his co-workers ${ }^{19}$ for iron(III) porphyrins, the crucial factors that determine the exchange rate are the electron density of the metal centre and the steric decompression of the complex. The dissociative activated water 
exchange is faster when the electron density on the metal center is increased, weakening the metal-axial ligand (a water molecule) bonds, and when the peripheral substituents of the porphyrin are bulky sterically hindering the complex and extruding water molecules from the inner coordination sphere.

The peripheral 4-sulfonatophenyl substituents of the $\mathrm{Mn}^{\mathrm{III}} \mathrm{TSPP}^{3-}$ porphyrin are strong electron-donors that increase electron density at the central $\mathrm{Mn}$ (III) ion, which in turn labilizes axial water ligands and promotes the limiting dissociative waterexchange mechanism similarly to the analogous $\mathrm{Fe}(\mathrm{III})$ complex. In the case of $\left[\left(\mathrm{H}_{2} \mathrm{O}\right)_{2} \mathrm{Mn}^{\mathrm{III}} \mathrm{TE}-2-\mathrm{PyP}\right]^{5+}$ and $\left[\left(\mathrm{H}_{2} \mathrm{O}\right)_{2} \mathrm{Mn}^{\mathrm{III}} \mathrm{TnHex}-\right.$ $2-\mathrm{PyP}]^{5+}$, the substituents on the porphyrin rings are among the strongest electron withdrawing groups due to the positively charged aromatic nitrogens in ortho positions. The electron withdrawing strengthens the metal-axial water bonds which dissociation must be assisted by an incoming water molecule. The dissociation occurs simultaneously with the approach of an outer-sphere water molecule, i.e. the bond cleavage parallels the new metal-water bond formation. Thus the operative mechanism for the assisted water-exchange in $\left[\left(\mathrm{H}_{2} \mathrm{O}\right)_{2} \mathrm{Mn}^{\mathrm{III}} \mathrm{TE}-2-\mathrm{PyP}\right]^{5+}$ and $\left[\left(\mathrm{H}_{2} \mathrm{O}\right)_{2} \mathrm{Mn}^{\text {III }} \mathrm{TnHex}-2-\mathrm{PyP}\right]^{5+}$ is an interchange process resulting in a significantly lower reaction rate than observed for the $\left[\left(\mathrm{H}_{2} \mathrm{O}\right)_{2} \mathrm{Mn}^{\mathrm{III}} \mathrm{TSPP}\right]^{3-}$ complex. The lower activation enthalpies for the reactions of two positively charged complexes are therefore expected, since the metal-water bond cleavage in the transition state of the interchange mechanism is a concerted process with the new bond formation. Accordingly, the overall activation enthalpy must be significantly lower for the reaction following the interchange mechanism characterized by the dissociative mode of activation than for the reaction following the limiting dissociative mechanism that is likely to be the water-exchange of $\left[\left(\mathrm{H}_{2} \mathrm{O}\right)_{2} \mathrm{Mn}^{\text {IIITSPP }}\right]^{3-}$. However, it should be noted that, based on our results, a clear distinction between the $I_{\mathrm{d}}$ and $I_{\mathrm{a}}$ reaction mechanisms cannot be done; but is rather based on the similarity with the water exchange kinetics of the analogous iron(III) porphyrin complexes.

A rather small difference between the exchange rates of $\left[\left(\mathrm{H}_{2} \mathrm{O}\right)_{2} \mathrm{Mn}^{\mathrm{III}} \mathrm{TE}-2-\mathrm{PyP}\right]^{5+}$ and $\left[\left(\mathrm{H}_{2} \mathrm{O}\right)_{2} \mathrm{Mn}^{\mathrm{III}} \mathrm{TnHex}-2-\mathrm{PyP}\right]^{5+}$ complexes can be attributed to the different steric decompression of two porphyrins. The hexyl side chains hinder the metal centre somewhat more than the ethyls do; therefore, if the associative mode of activation were operating, one would expect a decrease of the exchange rate due to a somewhat more difficult approach of the entering water molecule to the central metal ion. On the other hand, if the dissociative character of the interchange mechanism is proposed, the axial water molecules are expected to be slightly easier expelled from the $\left[\left(\mathrm{H}_{2} \mathrm{O}\right)_{2} \mathrm{Mn}^{\text {III }} \mathrm{TnHex}-2-\mathrm{PyP}\right]^{5+}$ complex which is in agreement with the measured data. Still, the difference between the exchange rates is too small to be taken as a definite criterion for distinction between the $I_{\mathrm{d}}$ and $I_{\mathrm{a}}$ mechanisms.

The introduction of a porphyrin chelate around the $\mathrm{Fe}(\mathrm{III})$ center labilizes the coordinated water molecules in the axial position by inducing electron density on the metal center. It was reported that the water exchange rate constants on the $\mathrm{Fe}(\mathrm{III})$ porphyrins are ca. $10^{4}$ times larger than on the hexa-aqua system. ${ }^{19}$ Based on the similarity between the size of the high spin Fe(III) and Mn(III) ions, and the close resemblance of the intimate water exchange mechanisms observed for these two ions, the rate constant of the water exchange on aqua manganese(III) ion can be estimated to be in the range of $\sim 10^{2}-10^{3} \mathrm{~s}^{-1}$, depending whether our data on $\left[\left(\mathrm{H}_{2} \mathrm{O}\right)_{2} \mathrm{Mn}^{\text {III TSPP }}\right]^{3-}$ are compared to the rate constant of the water exchange on $\left[\left(\mathrm{H}_{2} \mathrm{O}\right)_{2} \mathrm{Fe}^{\mathrm{III}} \mathrm{TSPP}\right]^{3-}$ reported in ref. 32 or in ref. 19 , respectively.

In addition, we calculated the residence time of the water coordinated in $\left[\left(\mathrm{H}_{2} \mathrm{O}\right)_{2} \mathrm{Mn}^{\mathrm{III}} \mathrm{TSPP}\right]^{3-}$ at room temperature to be $36 \mathrm{~ns}$. Thus the applied $10 \mathrm{~ns}$ in the analysis of NMRD curves of relaxivity of water protons have not been far from the reality. Therefore, the interpretation of the anomalous relaxivity of $\left[\left(\mathrm{H}_{2} \mathrm{O}\right)_{2} \mathrm{Mn}^{\text {III }} \mathrm{TSPP}\right]^{3-}$, which was recently confirmed by the density functional theory calculations of anomalous spin-polarization mechanism for high-spin manganese(III) porphyrin complexes, ${ }^{42}$ is probably correct, or at least it is not the result of the misused water residence time. ${ }^{28,29}$

\section{Conclusions}

Via temperature-dependent ${ }^{17} \mathrm{O}$ NMR measurements and adequate data treatment we found that the crucial factors that determine the rates and the mechanisms of the water-exchange reactions of manganese(III) porphyrins are identical to those for iron(III) porphyrins: the charge density of the metal centre and the steric decompression of the complex. It was also observed that the rates of the water exchange for $\mathrm{Mn}$ (III) porphyrins are almost a magnitude higher than for Fe(III) porphyrins of similar structure and charge. Our results provide evidence that the outer-sphere contribution to the reduced relaxations rates and the chemical shift are negligible for the studied Mn(III) porphyrin solutions.

The suggested inner sphere electron transfer mechanism for the reactions of the two positively charged $\mathrm{Mn}$ (III) porphyrins with various biologically important free radicals is further confirmed by the magnitude of water-exchange rate constants obtained in the present study.

It is also worth mentioning that for $\left[\mathrm{Mn}{ }^{\text {III TSPP }}\right]^{3-}$ the measured residence time of water molecules is in good agreement with the theoretically assumed from ${ }^{1} \mathrm{H}$ NMRD profiles.

\section{Acknowledgements}

The authors thank the Croatian-Hungarian Joint Research Fund (TéT: Cro-11/2006), Hungarian Scientific Research Fund (OTKA: K68668 and T49044 (IN64289), and TAMOP 4.2.208/12 CHEMIKUT and the Croatian Ministry of Science (MZOŠ: 006-0061247-0009) for their financial support. For providing the IBB gradient probe head GVOP 1.2.3 0154/3 grant is also acknowledged. IBH is thankful to Duke University's CTSA grant 1 UL 1 RR024128-01 from NCRR/NIH.

\section{Notes and references}

1 I. B. Halliwell and J. M. C. Gutteridge, Free Radicals in Biology and Medicine, 4th Edition, Biosciences, Oxford, 2007.

2 I. Spasojević and I. Batinić-Haberle, Inorg. Chim. Acta, 2001, 317, 230242.

3 I. Batinić-Haberle, Methods Enzymol., 2002, 349, 223-233.

4 I. Batinić-Haberle, I. Spasojević, P. Hambright and I. Fridovich, J. Chem. Soc., Dalton Trans., 2002, 2689-2696.

5 D. Lahaye, K. Muthukumaran, C.-H. Hung, D. Gryko, J. S. Rebouças, I. Spasojević, I. Batinić-Haberle and J. S. Lindsey, Bioorg. Med. Chem., 2007, 15, 7066-7086. 
6 J. S. Rebouças, I. Spasojević, D. H. Tjahjono, A. Richaud, F. Méndez, L. Benov and I. Batinić-Haberle, Dalton Trans., 2008, 1233-1242.

7 I. Batinić-Haberle, L. Benov, I. Spasojević and I. Fridovich, J. Biol. Chem., 1998, 273, 24521-24528.

8 I. Batinić-Haberle, I. Spasojević, P. Hambright, L. Benov, A. L. Crumbliss and I. Fridovich, Inorg. Chem., 1999, 38, 4011-4022.

9 I. Batinić-Haberle, I. Spasojević, R. D. Stevens, P. Hambright, P. Neta, A. Okado-Matsumoto and I. Fridovich, Dalton Trans., 2004, 16961702.

10 I. Batinić-Haberle, I. Spasojević, R. D. Stevens, B. Bondurant, A. Okado-Matsumoto, I. Fridovich, Ž. Vujasković and M. W. Dewhirst, Dalton Trans., 2006, 617-624.

11 A. Okado-Matsumoto, I. Batinić-Haberle and I. Fridovich, Free Radical Biol. Med., 2004, 37, 401-410.

12 B. J. Moeller, I. Batinić-Haberle, I. Spasojević, Z. N. Rabbani, M. S. Anscher, Ž. Vujasković and M. W. Dewhirst, Int. J. Rad. Oncol. Biol. Phys., 2005, 63, 545-552.

13 I. Spasojević, Y. Chen, T. J. Noel, Y. Yu, M. P. Cole, L. Zhang, Y. Zhao, D. K. St. Clair and I. Batinić-Haberle, Free Radical Biol. Med., 2007, 42, 1193-1200.

14 H. Saba, I. Batinić-Haberle, S. Munusamy, T. Mitchell, C. Lichti, J. Megyesi and L. A. MacMillan-Crow, Free Radical Biol. Med., 2007, 42, 1571-1578.

15 Z. N. Rabbani, I. Spasojević, X. Zhang, B. J. Moeller, J. Vasquez-Vivar, M. W. Dewhirst, Ž. Vujasković and I. Batinić-Haberle, Free Radical Biol. Med., 2009, 47, 992-1004.

16 G. Ferrer-Sueta, D. Vitturi, I. Batinić-Haberle, I. Fridovich, S. Goldstein, G. Czapski and R. J. Radi, J. Biol. Chem., 2003, 278, 27432 27438.

17 I. Batinić-Haberle, J. S. Reboucas and I. Spasojević, Antioxid. Redox Signal., 2009, DOI: 10.1089/ars.2009.2876.

18 J. S. Reboucas, G. DeFreitas-Silva, Y. M. Idemori, I. Spasojević, L. Benov and I. Batinić-Haberle, Free Radical Biol. Med., 2008, 45, 201210.

19 T. Schneppesieper, A. Zahl and R. van Eldik, Angew. Chem., Int. Ed., 2001, 40, 1678-1680.

20 J. A. Nelson and U. Schmiedl, Magn. Reson. Med., 1991, 22, 366371.

21 H. Nasu, Y. Takehara, S. Isogai, N. Kodaira, H. Takeda, T. Saga, S. Nakajima, I. Sakata and H. Sakahara, J. Magn. Reson. Imaging, 2004, 20, 294-299.
22 R. J. Fiel, D. A. Musser, E. H. Mark, R. Mazurchuk and J. J. Alletto, Magn. Reson. Imaging, 1990, 8, 255-259.

23 J. A. Nelson, U. Schmiedl and E. G. Shankland, Invest. Radiol, 1990, 25, S71-S73.

24 V. E. Yushmanov, T. T. Tominaga, I. E. Borissevitch, H. Imasato and M. Tabak, Magn. Reson. Imaging, 1996, 14, 255-261.

25 D. A. Place, P. J. Faustino, K. K. Berghmanns, P. C. M. van Zijl, A. S. Chesnick and J. S. Cohen, Magn. Reson. Imaging, 1992, 10, 919-928.

26 A. T. J. Klein, F. Rösch, H. H. Coenen and S. M. Qaim, Appl. Radiat. Isot., 2005, 62, 711-720.

27 T. Venkatraman, I. Batinić-Haberle, V. Mouraviev, H. Wang and C. Lascola, Novel Metalloporphyrins as Molecular MR Contrast Agents, accepted for presentation on the Joint Meeting of the European Society for Magnetic Resonance in Medicine and Biology and International Society of Magnetic Resonance in Medicine (ESMRMB / ISMRM) May 1-7 2010; Stockholm, Sweden, 2010.

28 N. Schaefle and R. Sharp, J. Phys. Chem. A, 2005, 109, 3267-3275.

29 S. H. Koenig, R. D. Brown III and M. Spiller, Magn. Reson. Med., 1987, 4, 252-260.

30 S. K. Sur and R. G. Bryant, J. Phys. Chem., 1995, 99, 4900-4905.

31 M. Blombergen and L. Morgan, J. Chem. Phys., 1961, 34, 842-850.

32 I. J. Ostrich, G. Liu, H. W. Dodgen and P. J. Hunt, Inorg. Chem., 1980, 19, 619-621.

33 A. L. van Geet, Anal. Chem., 1970, 42, 679-680.

34 R. V. Vold, J. S. Waugh, M. P. Klein and D. E. Phelps, J. Chem. Phys., $1968,48,3831-3832$.

35 D. H. Powel and A. E. Merbach, Magn. Reson. Chem., 1994, 32, 739 745.

36 T. J. Swift and R. E. Connick, J. Chem. Phys., 1962, 37, 307-320, (ibid, 1964, 41, 2553-2554).

37 Y. Ducommun, K. E. Newman and A. E. Merbach, Inorg. Chem., 1980, 19, 3696-3703.

38 A. Harriman and G. Porter, J. Chem. Soc., Faraday Trans. 2, 1979, 75, $1532-1544$

39 I. Spasojević, I. Batinić-Haberle, J. S. Reboucas, Y. M. Idemori and I. Fridovich, J. Biol. Chem., 2003, 278, 6831-6837.

40 R. M. Fuoss, J. Am. Chem. Soc., 1958, 80, 5059-5061.

41 J. S. Summers, K. Base, H. Boukhalfa, J. E. Payne, B. R. Shaw and A. L. Crumbliss, Inorg. Chem., 2005, 44, 3405-3411.

42 R.-J. Cheng, S.-H. Chang and K.-C. Kuo-Cheng Hung, Inorg. Chem., 2007, 46, 1948-1950. 